CASE REPORT

\title{
Chronic myeloid leukaemia with extreme thrombocytosis
}

\author{
Shailendra Prasad Verma, ${ }^{1}$ Arunkumar Subbiah, ${ }^{2}$ Sajini Elizabeth Jacob, ${ }^{3}$ \\ Debdatta Basu ${ }^{3}$
}

${ }^{1}$ Department of Medicine, King George's Medical University, Lucknow, Uttar Pradesh, India ${ }^{2}$ Department of Medicine, JIPMER, Pondicherry, India ${ }^{3}$ Department of Pathology, JIPMER, Pondicherry, India

Correspondence to Dr Shailendra Prasad Verma, drspkgmu@rediffmail.com

Accepted 5 August 2015
CrossMark

To cite: Verma $S P$ Subbiah A, Jacob SE, et al. BMJ Case Rep Published online: [please include Day Month Year] doi:10.1136/ bcr-2014-204564

\section{SUMMARY}

We report two cases of chronic myeloid leukaemia (CML) with extreme thrombocytosis. The first patient was a 65-year-old man who presented with prolonged history of upper abdominal discomfort, anorexia and two episodes of recent gum bleeds without fever or other bleeding manifestations. He was a chronic smoker with no other comorbidities. Examination revealed moderate hepatosplenomegaly. On investigation, he was found to have extreme thrombocytosis $\left(3500000 / \mathrm{mm}^{3}\right.$ ) and leucocytosis with moderate anaemia. In view of the leucocytosis, he was investigated for $\mathrm{CML}$ and found to be positive for BCR-ABL by reverse transcription PCR (RT-PCR). He received imatinib $400 \mathrm{mg} /$ day and achieved complete haematological response at the end of 3 months. The second patient was a 7-year-old boy who presented with fever, cough and cold of 2-week duration. Examination revealed mild hepatomegaly with palpable spleen tip. Haemogram and peripheral smear revealed moderate leucocytosis with extreme thrombocytosis $\left(2800000 / \mathrm{mm}^{3}\right)$. On evaluation, he was found to be BCR-ABL positive and responded well to imatinib treatment. In both these cases, massive thrombocytosis was an unusual presentation of a wellknown entity, namely, CML. This degree of thrombocytosis is usually seen only in essential thrombocytosis.

\section{BACKGROUND}

Myeloproliferative neoplasms (MPNs) are relatively rare haematological malignancies. Chronic myeloid leukaemia (CML) is the commonest MPN and characterised by extreme leucocytosis, myelocyte bulge, basophilia, eosinophilia in peripheral blood and presence of underlying Philadelphia chromosome as a cytogenetic abnormality or BCR-ABL transcript as a molecular abnormality. Some patients of CML can have mild to moderate thrombocytosis. Essential thrombocytosis (ET) is characterised by moderate to severe thrombocytosis with underlying JAK2V617F mutation in about 50\% of cases. We report two unusual cases of patients who presented with extreme thrombocytosis and mild to moderate leucocytosis, which, on further investigations, turned out to be CML (BCR-ABL+, p210 transcript by reverse transcription PCR (RT-PCR)). Extreme thrombocytosis in a case of CML has very rarely been reported. Both patients responded to treatment with the tyrosine kinase inhibitor drug, imatinib, with complete haematological recovery at 3 months.

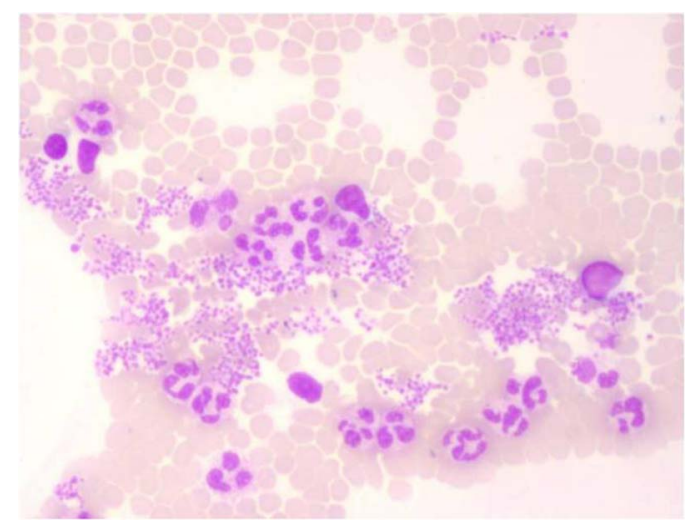

Figure 1 Peripheral smear of patient 1 showing marked tailing of platelets with platelet clumps (Leishman, $\times 100$ ).

\section{CASE PRESENTATION}

Patient 1: A 65-year-old man, a chronic smoker, presented with a history of upper abdominal discomfort, loss of appetite, significant lethargy and progressive weight loss of 1 year duration. He also had a cough with scant mucoid expectoration and progressive exertional breathlessness for a duration of 2 years. He reported exacerbation of respiratory symptoms during change of seasons. There was no history of fever, chest pain, haemoptysis, orthopnoea, paroxysmal nocturnal dyspnoea or wheezing. The patient also reported two episodes of gum bleeding over the last 2 months, which resolved spontaneously. There was no history of any other bleeding manifestation, swellings, or night sweats. The patient did not have any bleeding during his

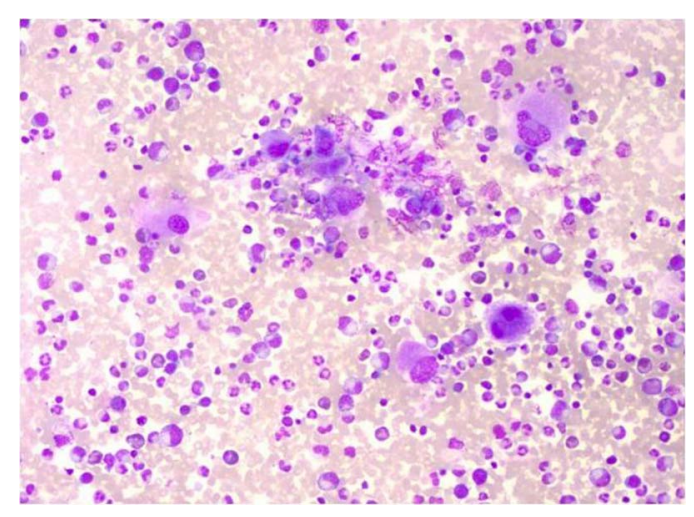

Figure 2 Bone marrow aspirate of patient 1 showing myeloid hyperplasia with increase in megakartocytes, a few of them showing monolobated forms (Leishman, $\times 100$ ). 


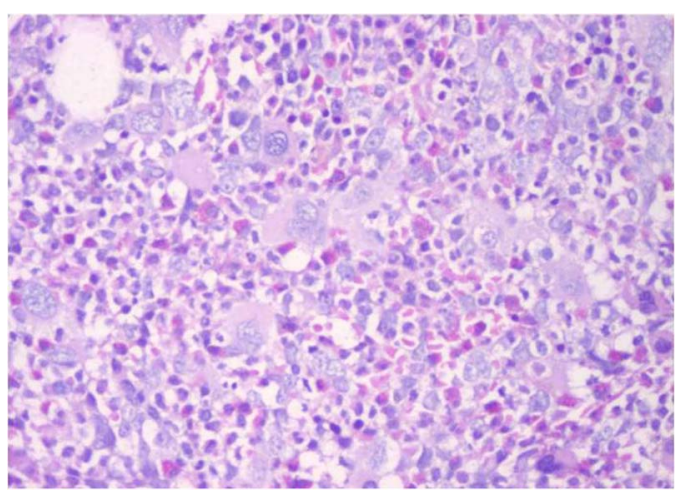

Figure 3 Bone marrow biopsy of patient 1 showing megakaryocytic hyperplasia with dwarf forms and monolobated forms ( $H \& E, \times 40)$.

hospital stay. He was not a diabetic or hypertensive and there was no history of contact with tuberculosis. He was diagnosed at another facility as a case of chronic obstructive pulmonary disease and received irregular treatment.

On examination, the patient's blood pressure was 140/ $90 \mathrm{~mm} \mathrm{Hg}$ and his pulse rate was regular, at $88 / \mathrm{min}$. He was afebrile with respiratory rate of $20 / \mathrm{min}$. General examination revealed normal oral hygiene, mild pallor and mild pedal oedema. Abdominal examination revealed moderate hepatosplenomegaly and respiratory system showed bilateral diffuse rhonchi (figures 1-3).

Patient 2: A 7-year-old child presented with a history of fever with cough and cold for a duration of 2 weeks. He did not have any bleeding manifestations or weight loss. Physical examination revealed normal oral cavity and mild pallor without any lymphadenopathy or sternal tenderness. Abdominal examination revealed mild hepatomegaly with palpable spleen tip. Table 1 shows the laboratory work up of both these patients (figure 4).

\section{DIFFERENTIAL DIAGNOSIS}

In view of the patient's markedly raised platelet count and leucocytosis, the possibility of MPN was considered. ET and CML were the most likely possibilities. Reactive causes were very less likely due to extreme thrombocytosis and associated leucocytosis.

\section{TREATMENT}

Awaiting reports of BCR-ABL and in view of marked leucocytosis and thrombocytosis, patient 1 was started on hydroxyurea. Day 5 after availability of BCR-ABL, imatinib was added. On day 10 , his platelet count reduced to $1500000 / \mathrm{mm}^{3}$; aspirin was added to the treatment and hydroxyurea was stopped.

Patient 2 was started on imatinib after availability of confirmatory reports.

\section{OUTCOME AND FOLLOW-UP}

Patient 1: At the end of 3 months, hepatosplenomegaly clinically subsided and anaemia improved. The patient achieved haemoglobin of $13.8 \mathrm{~g} / \mathrm{dL}$, total leucocyte count of $8100 / \mathrm{mm}^{3}$ with normal differential counts and platelet count of $149000 / \mathrm{mm}^{3}$. He achieved a complete haematological response.

Patient 2: This patient also responded very well to treatment with normalisation of platelet count at 3 weeks and complete haematological response at the end of 3 months.

\section{DISCUSSION}

CML is a MPN characterised by the presence of Philadelphia chromosome $\mathrm{t}(9: 22)$. CML is characterised by marked leucocytosis, myelocyte bulge, basophilia, eosinophilia and normal to mild thrombocytosis in peripheral blood. A fair number of patients may have mild thrombocytosis. Jameel and Jamil ${ }^{1}$ studied the clinicopathological profiles of 59 patients of CML and found that about $10 \%$ of patients had a platelet count of $>500000 / \mathrm{mm}^{3}$. Case reports of extreme thrombocytosis in CML are rare. Langabeer et al described an 80-year-old patient of CML with thrombocytosis (platelet count of $1400000 / \mathrm{mm}^{3}$ ). On RT-PCR, that patient was found to have a variant e19a2 BCR-ABL1 transcript. Treatment response could not be assessed well due to multiple treatment interruptions. ${ }^{2}$ Yamagata reported a case of CML with variant BCR-ABL transcript c3-e2. The patient had severe thrombocytosis and clinical features suggestive of essential thrombocytosis (ET) rather than that of a typical CML. The patient had poor response to interferon $\alpha .^{3}$ Kim $e t a l^{4}$ also reported a 51-year-old man who presented with extreme thrombocytosis (platelet count of $1594000 / \mathrm{mm}^{3}$ ) and leucocytosis. RT-PCR analysis for BCR-ABL arrangement showed presence of a b3a2 fusion gene. The patient responded to imatinib treatment.

Table 1 Relevant investigations performed during hospital stay

\begin{tabular}{|c|c|c|}
\hline Investigation & Patient 1 & Patient 2 \\
\hline Haemogram & $\begin{array}{l}\mathrm{Hb}: 9.9 \mathrm{~g} / \mathrm{dL} \text {, total WCC: } 66400 / \mathrm{mm}^{3} \text {, differential count: N88 L2, platelet } \\
\text { count: } 3500000 / \mathrm{mm}^{3}\end{array}$ & $\begin{array}{l}\mathrm{Hb}: 11.4 \mathrm{~g} / \mathrm{dL} \text {, total WCC: } 21200 / \mathrm{mm}^{3} \text {, differential count: N52 L32 } \\
\text { E4 B10, platelet count: } 2800000 / \mathrm{mm}^{3}\end{array}$ \\
\hline Peripheral smear & $\begin{array}{l}\text { Normocytic normochromic RBC, marked neutrophilic leucocytosis with } \\
\text { severe thrombocytosis (figure 1) }\end{array}$ & $\begin{array}{l}\text { Normocytic normochromic RBC, moderate leucocytosis with mild } \\
\text { basophilia and severe thrombocytosis (figure 4) }\end{array}$ \\
\hline LAP score & 50 (control: 324) & 0 (control: 286) \\
\hline Bone marrow aspiration & $\begin{array}{l}\text { Hypercellular marrow with basophilia, eosinophilia and mild increase in } \\
\text { megakaryocyte number with monolobated and multilobated forms and } \\
\text { occasional dwarf forms (figure 2) }\end{array}$ & $\begin{array}{l}\text { Hypercellular marrow with myeloid hyperplasia and increase in } \\
\text { number of megakaryocytes with clustering, hyperlobated as well as } \\
\text { dwarf forms, were seen }\end{array}$ \\
\hline Bone marrow biopsy & Hypercellular marrow with features suggestive of MPN (figure 3) & Hypercellular marrow with features suggestive of MPN/CML \\
\hline Serum LDH & $616.8 \mathrm{IU} / \mathrm{L}$ & Not done \\
\hline USG of the abdomen & Moderate hepatosplenomegaly with mild prostatomegaly & Mild hepatosplenomegaly \\
\hline RT-PCR for BCR-ABL & Positive for p210 transcript & Positive for p210 transcript \\
\hline JAK-2 V617F mutation & Negative & Not performed \\
\hline CECT of the thorax & Emphysematous lungs, no lymphadenopathy & \\
\hline
\end{tabular}




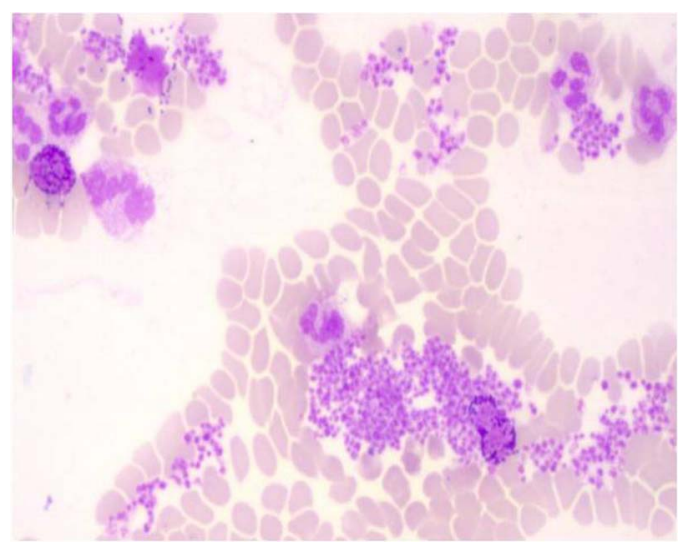

Figure 4 Peripheral smear of patient 2 showing marked thrombocytosis (Leishman, $\times 100$ ).

Shen et al also reported a case of CML mimicking ET. Fluorescence in situ hybridisation (FISH) and RT-PCR confirmed the diagnosis. Morphologically, bone marrow aspiration and biopsy revealed megakaryocytes that were smaller than normal and had a typical hyperlobated round nuclei. ${ }^{5}$ At times,

\section{Learning points}

- Chronic myeloid leukaemia (CML) can rarely present with extreme thrombocytosis.

- Essential thrombocytosis becomes a close differential diagnosis.

- Sometimes thrombocythaemia may be the only peripheral blood finding in the chronic phase of CML.

- Variant BCR-ABL transcripts may be associated with extreme thrombocytosis in $\mathrm{CML}$, which can have a different response to drugs in comparison to typical CML.

- All patients with thrombocythaemia should be investigated for BCR-ABL translocation. leucocytosis, basophilia, peripheral immature cells and splenomegaly may be absent at the onset of disease or at the initial presentation to clinic, but may develop in later years. Rice and Popat reported two cases of women who initially presented with only severe thrombocytosis and vascular events (stroke, myocardial infarction) and later developed typical features of CML. The authors concluded that every case of ET should be tested for the Philadelphia chromosome. ${ }^{6}$ The literature also reveals case reports of Philadelphia positive $(\mathrm{Ph}+)$ ET without features of CML in peripheral blood. These cases were ultimately diagnosed as CML and thrombocytosis was considered as an early manifestation of the chronic phase of CML.?

In our cases, transcript analyses revealed a p210 transcript, confirmed by RT-PCR, and the patients responded extremely well to imatinib therapy.

Contributors SPV thoroughly evaluated the clinical history and physical findings, and worked up the case along with reviewing the literature. AS helped in collecting the clinical history and planning work up of the patients. SEJ and DB helped in haematological work up of the patients and review of the literature.

Competing interests None declared.

Patient consent Obtained.

Provenance and peer review Not commissioned; externally peer reviewed.

\section{REFERENCES}

1 Jameel A, Jamil SN. Clinico-pathological profile of chronic myeloid leukemia. JPMI 2006;20:235-8.

2 Langabeer SE, McCarron SL, Kelly J, et al. Chronic myeloid leukemia with e19a2 BCR-ABL1 transcripts and marked thrombocytosis: the role of molecular monitoring. Case Rep Hematol. 2012:2012:458716.

3 Yamagata T, Mitani K, Kanda Y, et al. Elevated platelet count features the variant type of BCR/ABL junction in chronic myelogenous leukaemia. Br J Haematol 1996;94:370-2.

4 Kim SY, Jeon YL, Park TS. Chronic myeloid leukemia with extreme thrombocytosis. Korean J Haematol 2012;47:7.

5 Shen Q, Zhou JW, Zju GR et al. Chronic myeloid leukemia onset with marked thrombocythemia. Zhonqquo Shi Yan Xue Ye Xue Za Zhi 2006;14:247-51.

6 Rice L, Popat U. Every case of essential thrombocythemia should be tested for the Philadelphia chromosome. Am J Hematol 2005;78:71-3.

7 Michiels JJ, Berneman Z, Schroyens W, et al. Philadelphia(Ph) chromosome positive thrombocythemia without features of chronic myeloid leukemia in peripheral blood: natural history and diagnostic differentiation from Ph-negative essential thrombocythemia. Ann Hematol 2004;83:504-12.

Copyright 2015 BMJ Publishing Group. All rights reserved. For permission to reuse any of this content visit http://group.bmi.com/group/rights-licensing/permissions.

BMJ Case Report Fellows may re-use this article for personal use and teaching without any further permission.

Become a Fellow of BMJ Case Reports today and you can:

- Submit as many cases as you like

- Enjoy fast sympathetic peer review and rapid publication of accepted articles

- Access all the published articles

- Re-use any of the published material for personal use and teaching without further permission

For information on Institutional Fellowships contact consortiasales@bmjgroup.com

Visit casereports.bmj.com for more articles like this and to become a Fellow 